\title{
Remote ischemic preconditioning and thoracoabdominal aneurysm repair: Can an arm save a cord (or legs)?
}

\author{
Maral Ouzounian, MD, PhD, Thomas F. Lindsay, MDCM, MSc, and Thomas L. Forbes, MD
}

\footnotetext{
From the Division of Cardiac Surgery, Department of Surgery, Peter Munk Cardiac Centre, University of Toronto, Toronto, Canada.

Disclosures: Authors have nothing to disclose with regard to commercial support.

Received for publication Nov 20, 2015; accepted for publication Nov 20, 2015; available ahead of print Dec 18, 2015.

Address for reprints: Maral Ouzounian, MD, PhD, Peter Munk Cardiac Centre, 200 Elizabeth St, 4N-464, Toronto, ON M5G 2C4, Canada (E-mail: Maral.ouzounian@uhn.ca).

J Thorac Cardiovasc Surg 2016;151:616-7

$0022-5223 / \$ 36.00$

Copyright (c) 2016 by The American Association for Thoracic Surgery

http://dx.doi.org/10.1016/j.jtcvs.2015.11.036
}

Spinal cord ischemia (SCI) remains too common after open thoracoabdominal aortic aneurysm repair. This devastating complication has been relatively resistant to advances in anesthesia (neuromonitoring, cerebrospinal fluid drainage, hemodynamic management) and open surgical technique (distal perfusion, sequential clamping, reimplantation of segmental arteries). Despite these adjuncts, the incidence of SCI remains troubling, at $5 \%$ to $11 \%$ in contemporary series, ${ }^{1-3}$ and it requires new therapies.

Since its original description ${ }^{4}$ in 1986, preconditioning has piqued investigators' interest as a tool to minimize, or prevent, the sequelae of ischemic injury. Remote ischemic preconditioning (RIPC) has been most commonly investigated with respect to cardioprotection, ${ }^{5}$ and still is, despite recent randomized trials that failed to show its benefit in coronary surgery. ${ }^{6,7}$ The role of preconditioning has been explored in the central nervous system ${ }^{8}$ and the spinal cord, where a more "direct" mode of preconditioning has been utilized to promote collateral vessel development. These strategies have included endovascular coil embolization of segmental arteries prior to thoracoabdominal aortic aneurysm repair, ${ }^{9}$ and staging of extensive endovascular repairs. ${ }^{10}$ RIPC is attractive, though, given its simplicity and safety. 6,7

Haapanen and colleagues ${ }^{11}$ report an experimental porcine study examining the effect of RIPC on SCI after ligation of the left subclavian and segmental arteries. The authors observed improved motor evoked potential (MEP) amplitude and shortened onset latency in the right hind limb of animals that received RIPC. This favorable response was attenuated in the left hind limb. No significant differences were found between the 2 groups in neurologic assessment, spinal cord infarction score, and neuron degeneration by histology.

The authors should be congratulated on a well conducted study using established methodologies in a clinically relevant porcine model of SCI. The care of the animals, anesthetic management, and conduct of surgery were

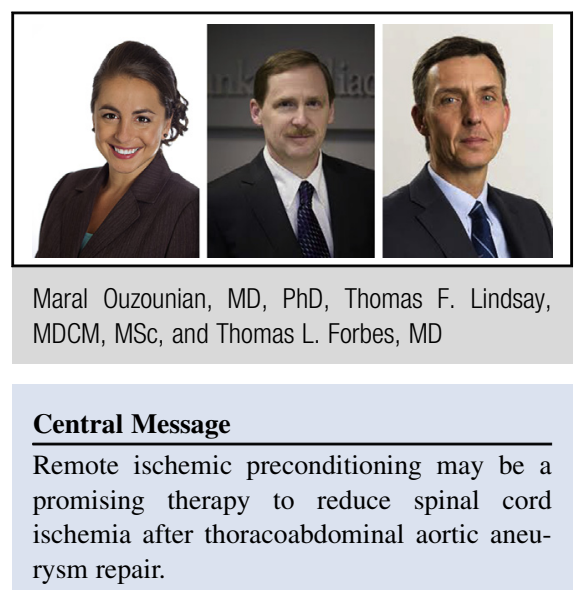

See Article page 777.

See Editorial Commentary page 786.

carefully standardized. The type of anesthesia, in particular, is well known to affect the interpretation of MEPs, as well as the effectiveness of RIPC, and must be considered in the design and interpretation of similar studies. Two observations require further study: RIPC itself caused an increase in MEPs before the onset of SCI; and the beneficial effect of RIPC was observed only in the right hind-limb MEP signals, a laterality of response not adequately explained by the data or the authors.

The major limitation of this paper is failure to demonstrate clinical benefit of RIPC in the animals. Although MEPs are often used as a surrogate marker of spinal cord function, the false positive rate is high, and a clinically meaningful endpoint of neurologic assessment with a larger sample size and longer surveillance of the animals after emergence from anesthesia would have made these preliminary results more convincing.

In summary, the authors have identified a potential novel therapeutic effect of RIPC to protect the spinal cord that may be relevant to patients undergoing thoracoabdominal aortic aneurysm repair. These preliminary observations should be investigated further in animal studies exploring the mechanism and pathophysiology of this effect. In addition, future studies should determine the clinical efficacy of this therapy in human trials of patients undergoing thoracoabdominal aortic aneurysm repair. 


\section{References}

1. Conrad MF, Cambria RP. Contemporary management of descending thoracic and thoracoabdominal aortic aneurysms: endovascular versus open. Circulation. 2008; 117:841-52

2. Griepp RB, Griepp EB. Spinal cord protection in surgical and endovascular repair of thoracoabdominal aortic disease. J Thorac Cardiovasc Surg. 2015; 149(2 Suppl):S86-90.

3. LeMaire SA, Price MD, Green SY, Zarda S, Coselli JS. Results of open thoracoabdominal aortic aneurysm repair. Ann Cardiothorac Surg. 2012;1:286-92.

4. Murry CE, Jennings RB, Reimer KA. Preconditioning with ischemia: a delay of lethal cell injury in ischemic myocardium. Circulation. 1986;74:1124-36.

5. Aimo A, Borrelli C, Giannoni A, Pastormerlo LE, Barison A, Mirizzi G, et al. Cardioprotection by remote ischemic conditioning: mechanisms and clinical evidences. World J Cardiol. 2015;7:621-32.

6. Meybohm P, Bein B, Brosteanu O, Cremer J, Gruenewald M, Stoppe C, et al; RIPHeart Study Collaborators. A multicenter trial of remote ischemic preconditioning for heart surgery. N Engl J Med. 2015;373:1397-407.

7. Hausenloy DJ, Candilio L, Evans R, Ariti C, Jenkins DP, Kolvekar S, et al: ERICCA Trial Investigators. Remote ischemic preconditioning and outcomes of cardiac surgery. N Engl J Med. 2015;373:1408-17.

8. Dezfulian C, Garrett M, Gonzalez NR. Clinical application of preconditioning and postconditioning to achieve neuroprotection. Transl Stroke Res. 2013;4: 19-24.

9. Etz CD, Debus ES, Mohr FW, Kolbel T. First-in-man endovascular preconditioning of the paraspinal collateral network by segmental artery coil embolization to prevent ischemic spinal cord injury. J Thorac Cardiovasc Surg. 2015;149:1074-9.

10. O'Callaghan A, Mastracci TM, Eagleton MJ. Staged endovascular repair of thoracoabdominal aortic aneurysms limits incidence and severity of spinal cord ischemia. J Vasc Surg. 2015;61:347-54.e1.

11. Haapanen H, Herajärvi J, Arvola O, Anttila T, Starck T, Kallio M, et al. Remote ischemic preconditioning protects the spinal cord after ischemic insult: an experimental porcine study. J Thorac Cardiovasc Surg. 2016;151: $777-85$. 